\title{
Inhibition of GH Releasing Factor (GRF)-Induced GH Secretion by Intraruminal Infusion of Volatile Fatty Acids (VFA) in Sheep
}

\author{
Nobuyoshi MATSUNAGA, TAISEI GOKA, Ki TAeg NAM, Shinichi ODA, \\ AKIRA OHNEDA*, AND YASUYUKI SASAKI \\ Department of Animal Physiology, Faculty of Agriculture, Tohoku University, Sendai 981, and \\ *Semine Prefectural Hospital, Miyagi 989-45, Japan
}

\begin{abstract}
A VFA mixture solution containing acetate, propionate and butyrate (the molar ratio of acetate, propionate and $n$-butyrate $=61.7: 24.3: 14.0)$ was infused into the rumen at various rates $(53.5,107$ and $214 \mu \mathrm{mol} \mathrm{kg}^{-1} \mathrm{~min}^{-1}$ ) over $6 \mathrm{~h}$ to examine the effects on basal and growth hormone-releasing factor (GRF, $0.25 \mu \mathrm{g} \mathrm{kg}^{-1}$ )-induced increase in secretion of $\mathrm{GH}$, insulin, glucagon and somatostatin (SRIF) in five castrated male sheep. Intraruminal infusion of the VFA mixture into the 18-h-fasted animals at the rates of 53.5, 107 and $214 \mu \mathrm{mol} \mathrm{kg-1} \mathrm{min}^{-1}$ finally raised the total intraruminal VFA concentration from 91.4 to $100.2(P>0.05), 175.9(P<0.05)$ and $234.5(P<0.05) \mathrm{mmol} l^{-1}$, respectively. A preliminary experiment showed that an infusion rate of $107 \mu \mathrm{mol} \mathrm{kg}^{-1} \mathrm{~min}^{-1}$ mimics the postprandial increase in ruminal VFA. The basal plasma GH concentrations ( 2 to $4 \mathrm{~h}$ after the start of VFA infusion) and the area under the profiles for GH release in response to the intravenous GRF injection, which was done $4 \mathrm{~h}$ after the start of VFA infusion, were significantly decreased by the VFA infusion rates of 107 and $214 \mu$ mol $\mathrm{kg}^{-1} \min ^{-1}$. Furthermore, the VFA infusion noticeably increased basal plasma concentrations of insulin, but it scarcely changed the basal levels of glucagon, SRIF and glucose. From these results we conclude that an increase in the ruminal VFA concentration, even within the physiological range, would suppress $\mathrm{GH}$ secretion from the ovine anterior pituitary, and that the postprandial rise in the ruminal VFA concentration may be one of the factors normally suppressing GH secretion in sheep.
\end{abstract}

Key words: GH, GH-releasing factor, Volatile fatty acids, Sheep

(Endocrine Journal 44: 133-140, 1997)

IN RUMINANT animals feeding caused a rapid and significant decrease in basal [1-4] and GHreleasing factor (GRF)-induced GH secretion [5]. Trenkle [5] and Tindal et al. [6] found that feeding, anticipation of being fed or artificial distention of the cranial sac of the rumen with a water-filled balloon reduced basal and GRF-induced GH secretion. These findings suggest that the visual

Received: May 17, 1996

Accepted: October 18, 1996

Correspondence to: Dr. Yasuyuki SASAKI, Department of Animal Physiology, Faculty of Agriculture, Tohoku University, Amamiyamachi, Sendai 981, Japan and mechanical stimuli accompanying by feeding are involved in the mechanism of the postprandial $\mathrm{GH}$ decrease.

Although large quantities of volatile fatty acids (VFA) are produced from dietary carbohydrates by microbial fermentation in the rumen, to meet a large proportion of the requirements for energy and cause an increase in the secretion of metabolic hormones such as insulin and glucagon [1, 7], little attention has been paid to $\mathrm{GH}$ secretion following feeding in ruminants. The results that have been published are conflicting [1, 8-10]. In our previous study [11], intravenous infusion of propionate or butyrate at rates of 3,10 and $30 \mu \mathrm{mol} \mathrm{kg}^{-1} \mathrm{~min}^{-1}$, 
significantly suppressed the increase in GRFinduced GH secretion in sheep. In view of these results we suggested that VFA is one of the factors which regulate $\mathrm{GH}$ secretion in this species [11]. Recently, Oshibe et al. [12] also reported that intraruminal injection of butyrate rapidly decreased the plasma GH concentration in cattle. These results suggest that pharmacologically large doses of VFA exert an inhibitory effect on GH secretion in spite of their stimulatory effects on pancreatic hormone secretion, but it has not been examined whether or not VFA are physiologically involved in the regulation of the secretion of these hormones essential to intermediary metabolism.

We therefore carried out the present series of experiments to determine if the artificially increased ruminal VFA concentration induced by an infusion of VFA mixture into the rumen, to the extent commonly seen after feeding, suppresses GH secretion. The study established that the increase in the ruminal VFA concentration significantly suppressed basal and GRF-induced GH secretion in sheep.

\section{Materials and Methods}

\section{Animals}

Five adult castrated male sheep were used (42.7$48.7 \mathrm{~kg}$ ). The sheep were housed in metabolic cages and fed alfalfa pellets at $2 \%$ of body weight in a single meal at $2100 \mathrm{~h}$. Water was available continuously. At least 5 months before the experiments began, surgery for exteriorization of the carotid artery and insertion of a rumen cannula was done under general anesthetic as described previously [11]. At least a week before the experiments, a polyethylene catheter for GRF injection was inserted into the jugular vein, and was kept patent by daily flushing with a sterile solution of trisodium citrate [11].

\section{Experimental procedures}

Experiments were performed at 7-day intervals. At least an hour before the experiment began, an indwelling $7.0 \mathrm{~cm}$ long catheter (Top Co., Tokyo) for blood sampling was inserted into the exteriorized carotid artery. The sheep were intravenously injected through the catheter with a $3 \mathrm{~m} l$ volume of GRF (1-44) $\mathrm{NH}_{2}$ (ovine sequence, Peninsula, lot No. 006825) dissolved in sterile saline at a dose of $0.25 \mu \mathrm{g} \mathrm{kg}^{-1}$ at $4 \mathrm{~h}$ after the onset of an intraruminal VFA infusion through the cannula.

To assess the effects of VFA on the basal and GRF-induced GH secretion, a VFA mixture solution ( $\mathrm{pH} 5.0$ adjusted with sodium hydroxide) containing acetic, propionic and $n$-butyric acid at the molar ratio of 61.7:24.3:14.0 was intraruminally infused through the rumen cannula over a period of $6 \mathrm{~h}$ at a rate of $53.5,107$ or $214 \mu \mathrm{mol} \mathrm{kg} \mathrm{kg}^{-1} \mathrm{~min}^{-1}$ with a peristaltic tube pump $(1 \mathrm{ml} \mathrm{min}-1)$. From the results of a preliminary experiment, the molar ratio of each acid in the VFA mixture solution was determined by measuring the VFA concentrations in the ruminal fluid, and an infusion at the rate of $107 \mu \mathrm{mol} \mathrm{kg}{ }^{-1} \min ^{-1}$ was shown to mimic the postprandial increase in ruminal VFA (not shown). An inorganic solution, the electrolyte composition of which was similar to that of the rumen (Warner solution) [13], was infused as the control. GRF injection was carried out $4 \mathrm{~h}$ after the start of the ruminal infusion. Samples of arterial blood were collected in heparinized syringes from $2 \mathrm{~h}$ before to $6 \mathrm{~h}$ after the srart of the infusion of VFA or Warner solution at every 15 min until the GRF injection, and then at 5, 10, 15, 20, 30, 45, 60, 75, 90, 105 and 120 min postinjection. Each blood sample was immediately cooled in ice water and was centrifuged for $10 \mathrm{~min}$ at $12,000 \mathrm{rpm}$ at $4{ }^{\circ} \mathrm{C}$. A portion of the plasma was deproteinized with 50 $\mathrm{mg} \mathrm{m} l^{-1}$ trichloroacetic acid and the supernatant was stored at $-25^{\circ} \mathrm{C}$ until glucose was determined by the glucose oxidase method of Huggett and Nixon [14]. The remaining plasma was divided into four portions and stored at $-25^{\circ} \mathrm{C}$ until hormone assay. The first portion contained 0.05 mmol benzamidine (benzamidine hydrochloride, Sigma) per $\mathrm{ml}$ of blood for glucagon assay and the second portion contained $500 \mathrm{KIU}$ aprotinin (Trasylol, Bayer) per $\mathrm{ml}$ of blood for somatostatin (SRIF) assay. For the measurement of ruminal VFA concentrations, rumen fluid was also sampled through the rumen cannula before the start of blood sampling and after the cessation of ruminal infusion. 


\section{Analyses}

Plasma concentrations of insulin, glucagon and GH were assayed by a double antibody radioimmunoassay [11, 15-19]. The insulin assay had a minimum detectable concentration of $1.1 \mu \mathrm{U}$ $\mathrm{m} l^{-1}$. Inter- and intra-assay coefficients of variation were 9.5 and $4.5 \%$, respectively. The glucagon assay had a minimum detectable concentration of $31.2 \mathrm{pg} \mathrm{m}^{-1}$. Inter- and intra-assay coefficients of variation were 10.5 and $6.3 \%$, respectively. Plasma $\mathrm{GH}$ assay was also performed as described previously $[11,19]$. Briefly, $\mathrm{GH}$ was assayed by a double antibody method with ovine $\mathrm{GH}$ antiserum (NIDDK-anti-oGH-2, AFP-C0123080). The standard was ovine GH (NIDDK-oGH-I-5, AFP6762B), a gift from NIDDK. Bovine GH (bGH iodination grade $i 070$, lot 009) was purchased from UCB Bioproducts (Belgium) and was iodinated by the chloramine $\mathrm{T}$ method. The assay had a minimum detectable concentration of $0.99 \mathrm{ng} \mathrm{m}^{-1}$. Inter- and intra-assay coefficients of variation were 15.0 and $12.7 \%$, respectively.

SRIF was assayed with unextracted plasma by a dextran-coated charcoal method. Synthetic somatostatin (Sigma lot 77F-00572) was used as the standard. Antiserum (Amersham International; lots 9 and 11) and 3-125I-iodotyrosyl somatostatin (Amersham International) were purchased. The assay had a minimum detectable concentration of $12.9 \mathrm{pg} \mathrm{m} l^{-1}$. Inter- and intra-assay coefficients of variation were 17.9 and $6.9 \%$, respectively. Rumen fluid was immediately filtered through two layers of gauze and the supernatant was mixed with the same volume of $5 \mathrm{~N}$ phosphoric acid solution containing crotonic acid $\left(60 \mathrm{mmol} l^{-1}\right)$ as an internal standard and stored at $-25^{\circ} \mathrm{C}$ until VFA assay. The VFA concentration was determined by gas chromatography (G-80, Yanako, Japan).

\section{Statistics}

Mean values as well as the standard errors of the means were calculated. The data were assigned to four 2-h periods: the period before infusion of VFA (between -2 and $0 \mathrm{~h}$ ), the first period during VFA infusion before GRF injection (between 0 and $2 \mathrm{~h}$ ), the second period during VFA infusion before GRF injection (between 2 and $4 \mathrm{~h}$ ) and the period after GRF injection during VFA infusion (between 4 and $6 \mathrm{~h}$ ). Significant differences between doses of VFA mixture and between periods within each dose were analyzed by analysis of variance (ANOVA) followed by Duncan's multiple range test, with the General Linear Model (GLM) of the SAS program package (SAS Institute, Cary, NC). The incremental hormonal areas enclosed by the hormone concentration curves above basal levels (between -2 and $0 \mathrm{~h}$ ) were also calculated between 0 and $2 \mathrm{~h}$, between 2 and $4 \mathrm{~h}$ and between 4 and 6 $\mathrm{h}$, and statistically analyzed by ANOVA followed by Duncan's multiple range test.

\section{Results}

Total VFA concentrations in the ruminal fluid sampled before and after VFA infusion are shown in Fig. 1. The total VFA concentration of acetic, propionic and $n$-butyric acids pre-infusion was 91.4 $\pm 2.9 \mathrm{mmol} l^{-1}$, which became $51.5 \pm 6.1(P>0.05)$, $100.2 \pm 8.1(P>0.05), 175.9 \pm 12.9(P<0.05)$ and 234.5 $\pm 30.1(P<0.05) \mathrm{mmol} l^{-1}$, respectively, following the infusion of the 0 (Warner solution), 53.5, 107 and $214 \mu \mathrm{mol} \mathrm{kg}^{-1} \mathrm{~min}^{-1}$ VFA mixtures. The total VFA concentration (175.9 $\mathrm{mmol} l^{-1}$ ) sampled after

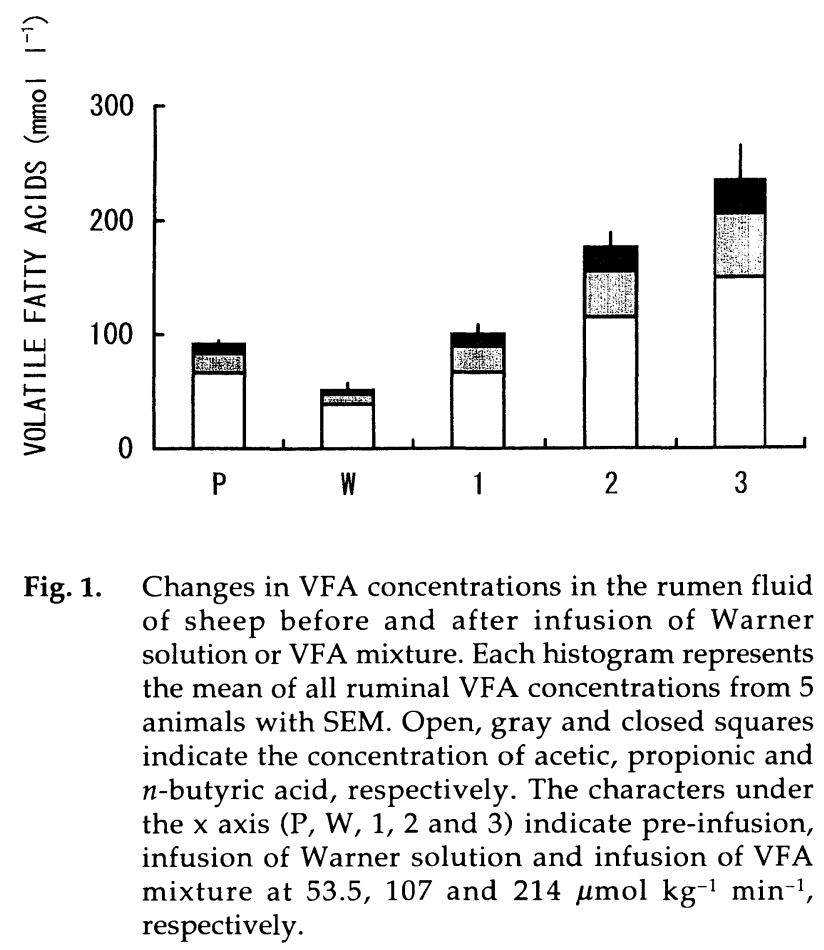


cessation of the infusion at $107 \mu \mathrm{mol} \mathrm{kg}-1 \min ^{-1}$ was similar to the report value used as a physiological dose [7].

The time course of the $\mathrm{GH}$ response is shown in Fig. 2. The mean basal concentrations of plasma $\mathrm{GH}$ before the start of infusion of the VFA mixture solution (time -2 to $0 \mathrm{~h}$ ) were $5.2 \pm 0.4,7.3 \pm 1.3$, $6.0 \pm 0.7$ and $5.3 \pm 1.1 \mathrm{ng} \mathrm{ml}^{-1}$ for the $0,53.5,107$ and $214 \mu \mathrm{mol} \mathrm{kg}^{-1} \mathrm{~min}^{-1}$ infusion rates, respectively. The $\mathrm{GH}$ concentration was not significantly $(P>0.05)$ changed during the first $2 \mathrm{~h}$ period of VFA mixture ( 0 to $2 \mathrm{~h}$ ) infusion, but gradually and significantly decreased to $2.7 \pm 0.4$ $(P<0.05)$ and $2.1 \pm 0.4(P<0.05) \mathrm{ng} \mathrm{ml}-1$ during the second $2 \mathrm{~h}$-period ( 2 to $4 \mathrm{~h}$ ) after the start of the 107 and $214 \mu \mathrm{mol} \mathrm{kg}^{-1} \mathrm{~min}^{-1}$ infusions, respectively. The GH concentrations for infusion of Warner solution and VFA mixture at the rate of $53.5 \mu \mathrm{mol} \mathrm{kg}{ }^{-1} \mathrm{~min}^{-1}$ were not significantly changed. The GRF $\left(0.25 \mu \mathrm{g} \mathrm{kg}^{-1}\right)$ injection, which was administered $4 \mathrm{~h}$ after the start of VFA infusion, significantly $(P<0.05)$ increased the plasma $\mathrm{GH}$ concentration, reaching the peak value $10 \mathrm{~min}$ after the injection. Peak concentrations were 104.4 $\pm 18.1(P<0.05), 92.7 \pm 11.7(P<0.05), 59.1 \pm 9.2$ $(P<0.05)$ and $30.7 \pm 12.6(P<0.05) \mathrm{ng} \mathrm{m}^{-1}$ for the 0 , $53.5,107$ and $214 \mu \mathrm{mol} \mathrm{kg}^{-1} \mathrm{~min}^{-1}$ infusion rates, respectively. The incremental areas of $\mathrm{GH}$ secretion after the GRF injection ( 4 to $6 \mathrm{~h}$ ) were $26.3 \pm 6.8$, $20.1 \pm 3.5,10.9 \pm 3.2$, and $2.9 \pm 3.7 \mathrm{ng} \mathrm{ml}^{-1} \mathrm{~min}^{-1}$, respectively. The areas during the 107 and 214 $\mu \mathrm{mol} \mathrm{kg}{ }^{-1} \mathrm{~min}^{-1}$ infusions were significantly $(P<0.05)$ smaller than that of the control.

The time course for insulin is shown in Fig. 3. There was no difference among the mean basal insulin concentrations for all groups before the VFA infusion. The mean basal concentration of insulin (7.3 $\pm 1.6 \mu \mathrm{U} \mathrm{ml}-1)$ was significantly increased to $19.3 \pm 4.0,33.1 \pm 11.8$ and $26.8 \pm 6.0 \mu \mathrm{U} \mathrm{ml} l^{-1}$ during the periods 0 to $2 \mathrm{~h}, 2$ to $4 \mathrm{~h}$ and 4 to $6 \mathrm{~h}$, respectively, by the start of the infusion of VFA mixture at the highest rate $\left(214 \mu \mathrm{mol} \mathrm{kg}^{-1} \mathrm{~min}^{-1}\right)$. The insulin incremental area for time 0 to $2 \mathrm{~h}(7.8$ $\left.\pm 4.2 \mu \mathrm{U} \mathrm{m} l^{-1} \min ^{-1}\right)$ was also significantly greater $(P<0.05)$ than that of the control $\left(-2.1 \pm 1.1 \mu \mathrm{U} \mathrm{m} l^{-1}\right.$ $\min ^{-1}$ ) during the same period, but the other infusion rates caused no significant change in insulin concentrations. GRF injection at $4 \mathrm{~h}$ after the start of VFA infusion significantly $(P<0.05)$ increased the plasma insulin concentration,

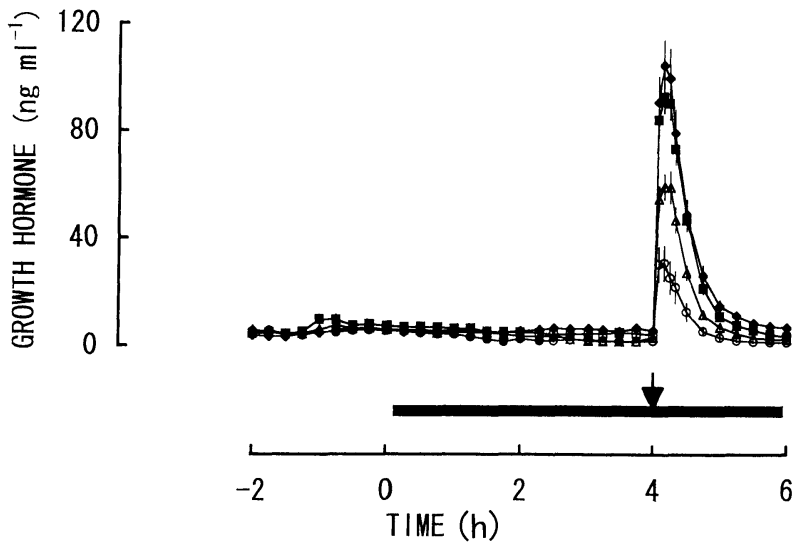

Fig. 2. Effect of intraruminal VFA infusion on the plasma concentrations of $\mathrm{GH}$ before and after the injection of GRF in 5 sheep. Each animal received an intraruminal infusion of Warner solution $(1 \mathrm{~m} l$ $\min ^{-1}, \diamond$ ), or VFA mixture containing $61.7 \%$ acetic, $24.3 \%$ propionic and $14.0 \% n$-butyric acid at the rates of $53.5(\square), 107(\Delta)$ and $214(0) \mu \mathrm{mol} \mathrm{kg} \mathrm{kg}^{-1}$ $\min ^{-1}$ for $6 \mathrm{~h}$. The arrow indicates the time of the intravenous injection of GRF $\left(0.25 \mu \mathrm{g} \mathrm{kg}^{-1}\right)$. Mean values for 5 sheep are shown with SEM (vertical bars). Data were assigned to 4 periods representing perfusion of VFA (between -2 and $0 \mathrm{~h}$ ), during VFA infusion before GRF injection (between 0 and 2 h), during VFA infusion before GRF injection (between 2 and $4 \mathrm{~h}$ ) and during VFA infusion after GRF injection (between 4 and $6 \mathrm{~h}$ ). Open symbols indicate significant differences between the control infusion and other infusions $(P<0.05)$ analyzed by ANOVA and Duncan's multiple range test using the General Linear Model procedure of the SAS program package on the incremental hormone areas enclosed by the hormone concentration curves above the basal levels.
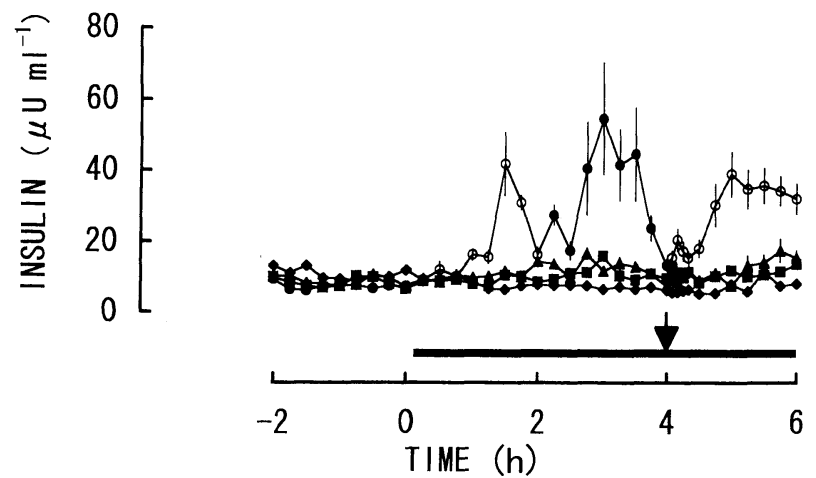

Fig. 3. Effect of intraruminal infusion of Warner solution or VFA mixture on the plasma concentrations of insulin before and after GRF injection in 5 sheep. The details of the procedures used are the same as for Fig. 2. 
reaching a peak value $300 \mathrm{~min}$ after the injection of $39.2 \pm 12.3(P<0.05) \mu \mathrm{U} \mathrm{m} l^{-1}$ at the $214 \mu \mathrm{mol}$ $\mathrm{kg}^{-1} \mathrm{~min}^{-1}$ infusion rate.

The time-course profiles of plasma glucagon and SRIF concentrations are shown in Figs. 4 and 5, respectively. The mean concentrations of glucagon and SRIF calculated from all of the observations through the series of experiments were $95.9 \pm 0.9$ and $166.2 \pm 1.7 \mathrm{pg} \mathrm{ml}^{-1}$, respectively. Any significant changes among the mean concentrations or incremental areas of glucagon or SRIF were not caused before or after the start of any infusion of VFA mixture or GRF injection used in the experiment.

The response of the plasma glucose concentration is shown in Fig. 6. There was no significant difference among the concentrations through the experiment for the infusion rates of 0 (control), 53.5 and $107 \mu \mathrm{mol} \mathrm{kg}^{-1} \mathrm{~min}^{-1}$. The start of the infusion of VFA mixture $214 \mu \mathrm{mol} \mathrm{kg} \mathrm{kg}^{-1} \mathrm{~min}^{-1}$ and GRF gradually and significantly increased the glucose concentration.

\section{Discussion}

The major finding in the present series of experiments is that an increase in the ruminal VFA concentration within the physiological range, caused by VFA mixture infusion into the rumen at rates of 107 and $214 \mu \mathrm{mol} \mathrm{kg}^{-1} \mathrm{~min}^{-1}$, caused a significant decrease in both basal and GRF-induced $\mathrm{GH}$ secretion. Feeding once per day, as in this experiment, commonly increases the ruminal VFA concentration to 120 to $200 \mathrm{mmol} l^{-1} 2 \mathrm{~h}$ after the start of feeding in this species [20]. A physiologically appropriate increase in the ruminal VFA concentration $\left(175.9 \mathrm{mmol} l^{-1}\right)$ was achieved in the present study by intraruminal infusion at the rate of $107 \mu \mathrm{mol} \mathrm{kg}{ }^{-1} \mathrm{~min}^{-1}$, which was suggested by the results obtained in goats by de Jong [7].

Although the intraruminal VFA infusion rate of $107 \mu \mathrm{mol} \mathrm{kg}^{-1} \mathrm{~min}^{-1}$ significantly reduced the basal and GRF-stimulated GH secretion, it did not significantly change the basal concentrations of insulin, glucagon and somatostatin, but VFA infusion at the rate of $214 \mu \mathrm{mol} \mathrm{kg} \mathrm{kg}^{-1} \mathrm{~min}^{-1}$ significantly increased insulin secretion. Oshibe et al. [12] recently injected a large amount of butyrate
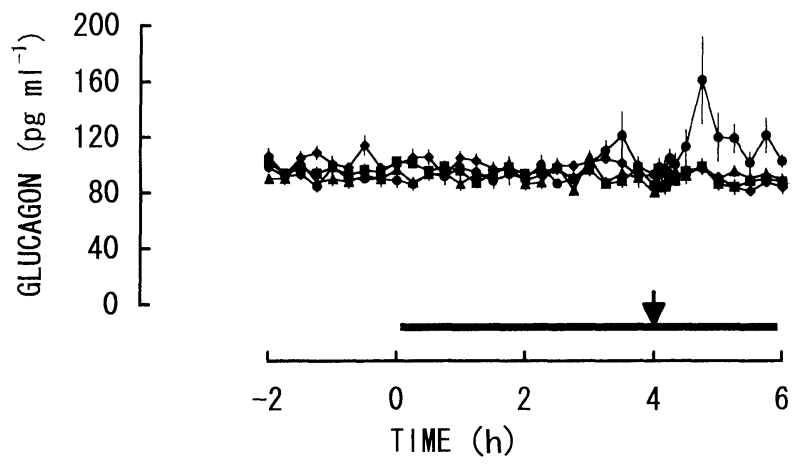

Fig. 4. Effect of intraruminal infusion of Warner solution or VFA mixture on the plasma concentrations of glucagon before and after GRF injection in 5 sheep. The details of the procedures used are the same as for Fig. 2.

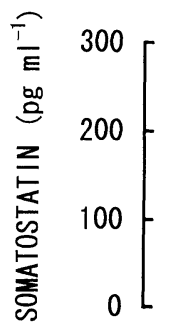
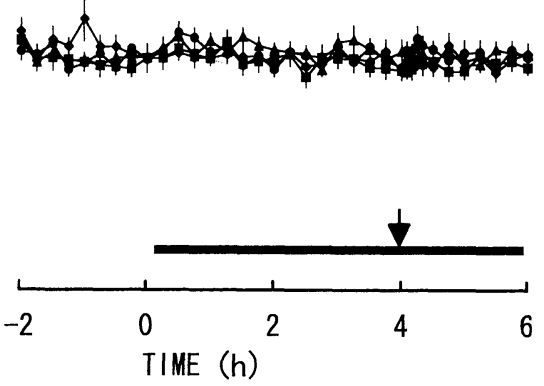

Fig. 5. Effect of intraruminal infusion of Warner solution or VFA mixture on the plasma concentrations of somatostatin before and after GRF injection in 5 sheep. The details of the procedures used are the same as for Fig. 2.
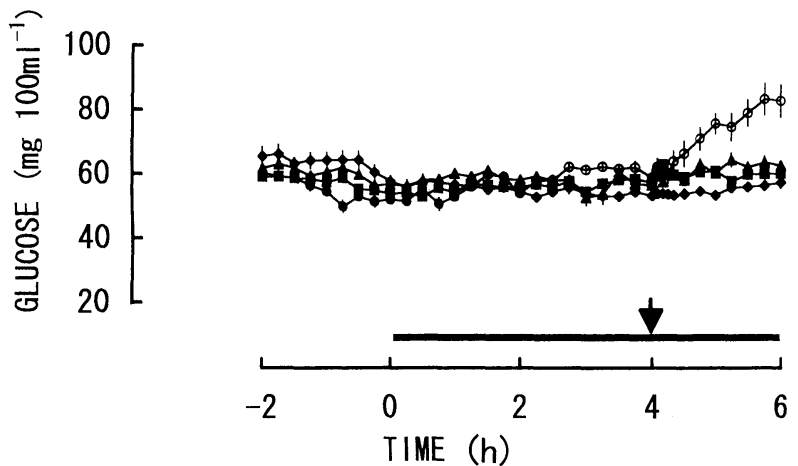

Fig. 6. Effect of intraruminal infusion of Warner solution or VFA mixture on the plasma concentrations of glucose before and after GRF injection in 5 sheep. The details of the procedures used are the same as for Fig. 2. 
$(20 \mathrm{mmol} \mathrm{kg}-1)$ into the rumen of dairy cows and found that it reduced the basal GH secretion, but increased insulin secretion. These findings indicate that the $107 \mu \mathrm{mol} \mathrm{kg} \mathrm{kg}^{-1} \mathrm{~min}^{-1}$ infusion rate increased the ruminal VFA concentration within a physiological range, and that the increase in the intraruminal VFA concentration achieved by this infusion rate was possibly more effective for activating inhibitory pathways for $\mathrm{GH}$ secretion than for activating the stimulatory pathways for pancreatic islet hormones.

Little is known about the mechanism by which an increased VFA concentration in plasma or the rumen suppresses basal and GRF-stimulated GH secretion. One possible mechanism causing a suppressed GH secretion induced by an increased ruminal VFA concentration could be via a neural pathway. That is, the action may be mediated by a reflex via chemo- and mechano-receptors in the rumen epithelium [24]. This assumption is supported by the findings that distention of the reticulo-rumen with a water-filled balloon and anticipation of being fed caused a rapid decrease in the GRF-stimulated GH response [5, 6]. On the mechanism for the action of VFA, chemo-receptors in the rumen epithelium may also be responsible since it is known that there are chemo-receptors sensitive to VFA in the rumen epithelium [24]. Recently we showed that GRF-stimulated GH secretion was significantly suppressed in a dosedependent manner during intravenous infusion for 40 min of propionate or butyrate, but not acetate [11]. But, reports on the effects of VFA administration into the blood stream of ruminants on GH secretion have been conflicting: some authors reported an increase in the $\mathrm{GH}$ concentration [8, 10], little effect [21, 22] or considerable inhibition [23] in response to VFA infusion. It therefore remains unclear whether the inhibitory action of increased ruminal VFA on GH secretion is attributable to increased blood VFA.

In the present study the suppressive action of ruminal VFA on the plasma GH concentration emerged 2-4 $\mathrm{h}$ after the start of intraruminal infusion of VFA, although the suppression of plasma $\mathrm{GH}$ concentration consists of an immediate fall followed by a sustained suppression after feeding [1-4]. It is therefore plausible that the inhibitory action of VFA on GH could explain the delayed and sustained phase in secretion, and the immediate and rapid decrease after feeding could be mediated by a neural reflex accompanied by feeding.

The infusion of a large amount of VFA, if introduced into the rumen or blood, increases insulin and glucagon secretion in a dose-dependent manner since it has been reported by many authors that increased ruminal and plasma VFA concentrations, more than those achieved by normal feeding, cause a rise in insulin and glucagon secretion in ruminants $[1,7,25,26]$. But, the normal plasma concentration of VFA and high rate of removal by the liver [27] does not support a role for plasma VFA as a physiological factor involved in islet hormone secretion. It is therefore unlikely that plasma VFA are physiological factors which modify islet hormone secretion in ruminants, although the role of propionate in eliciting an insulin response has recently been reevaluated [28].

The mechanisms by which increased plasma or rumen VFA increase islet hormone secretion are not fully understood. With respect to the mechanisms involved in the increase in insulin and glucagon secretion induced by the intravenous infusion of butyrate, Bloom and Edwards [26] suggested that in lambs a high plasma concentration of butyrate causes an increase in insulin secretion via excitation of sympathetic and parasympathetic nerves. But it is also known that propionate as well as butyrate can increase islet hormone secretion in in vitro preparations such as ovine pancreatic tissue segments [29] and isolated ovine islets [30], suggesting that the stimulatory effects of VFA, at least partly, involve direct actions on islet cells. Recently, Mineo and his co-workers $[31,32]$ have shown that the reception mechanism of VFA in causing an increase in glucagon and insulin secretion in A and B cells of ovine islets could be different. This is because the secretory sensitivity of A cells in response to iso-form VFA is much lower than that of B cells, and a carboxylic group bound to a hydrophobic group is indispensable to the potency of VFA for increasing the insulin release [31].

Lambs $[33,34]$ and other species $[35,36]$ have been reported to show a postprandial increase in insulin and SRIF secretion. Although SRIF exists in endocrine cells of the hypothalamus, pancreas and digestive tract, the postprandial increase in the plasma SRIF concentration is thought to be 
attributable only to the digestive tract [35]. The finding that intraruminal infusion of VFA did not change the peripheral plasma SRIF concentrations in the present experiment suggests that the suppression of the plasma $\mathrm{GH}$ concentration induced by VFA infusion was not mediated by an increased peripheral plasma SRIF concentration.

As shown in Fig. 6, the infusion rate of the VFA mixture solution at $214 \mu \mathrm{mol} \mathrm{kg-1} \mathrm{min}^{-1}$ significantly increased the plasma glucose concentration. This is probably caused by an increase in the blood $n$-butyrate and propionate concentrations induced by the ruminal VFA infusion at greater doses because these acids are known to increase the plasma glucose concentration in sheep $[25,31,32]$. Further increase in the plasma glucose concentration after the GRF injection might be due to the addition of a glycolytic action of GH to the action of VFA.

The present series of experiments have demonstrated that an increase in the ruminal VFA concentration, which is commonly seen after feeding when animals are fed once a day, causes a significant decrease in the plasma GH concentration without changing the plasma concentrations of insulin, glucagon or SRIF. This effect of VFA, specific for $\mathrm{GH}$ secretion from the anterior pituitary, suggests that this nutrient may be one of the regulatory factors controlling $\mathrm{GH}$ secretion in this species.

\section{Acknowledgments}

We are grateful to Dr. M. T. Rose (Japanese Institute of Animal Industry, Tsukuba) for his valuable advice on this manuscript. The authors greatly appreciate the National Hormone and Pituitary Program (NIDDK) for providing the GH antiserum and antigen.

\section{References}

1. Bassett JM (1972) Plasma glucagon concentration in sheep: Their regulation and relation to concentrations of insulin and growth hormone. Aust J Biol Sci 25: 1277-1287.

2. Basset JM (1974) Diurnal patterns of plasma insulin, growth hormone, corticosteroid and metabolite concentrations in fed and fasted sheep. Aust J Biol Sci 27: 169-181.

3. Driver PM, Forbes JM (1981) Episodic growth hormone secretion in sheep in relation to time of feeding, spontaneous meals and short term fasting. J Physiol [Lond] 317: 413-424.

4. Wallace AL, Bassett JM (1970) Plasma growth hormone concentrations in sheep measured by radioimmunoassay. J Endocr 47: 21-36.

5. Trenkle A (1989) Influence of feeding on growth hormone secretion and response to growth hormone-releasing factor in sheep. J Nutr 119: 6165.

6. Tindal JF, Blake LA, Simmonds AD, Hart IC, Mizuno H (1982) Control of growth hormone release in goats: Effects of vagal cooling, feeding and artificial distention of the rumen. Horm Metabol Res 14: 415-429.

7. de Jong A (1982) Patterns of plasma concentrations of insulin and glucagon after intravascular and intraruminal administration of volatile fatty acids in the goat. J Endocrinol 92: 357-370.

8. Bryce D, Yeh M, Funderburk C, Todd H, Hertelendy
F (1975) Studies on growth hormone secretion. VII. Effects of somatostatin on plasma GH, insulin, and glucagon in sheep. Diabetes 24: 842-850.

9. Hertelendy F, Machlin L, Kipnis DM (1969) Further studies on the regulation of insulin and growth hormone secretion in the sheep. Endocrinology 84: 192-199.

10. Sartin JL, Cummins KA, Kemppainen RJ, Carnes R, McClary DG, Williams JG (1985) Effect of propionate infusion on plasma glucagon, insulin and growth hormone concentrations in lactating dairy cows. Acta Endocrinologica 109: 348-354.

11. Matsunaga N, Nam KT, Kuhara T, Oda S, Ohneda A, Sasaki Y (1993) Inhibitory effect of volatile fatty acids on GRF-induced GH secretion in sheep. Endocr J 40: 529-537.

12. Oshibe A, Ishida M, Ando S, Oshio S, Hodate $K$ (1994) Responses of plasma growth hormone and insulin concentrations to intraruminal injections of $n$-butyrate and acetate in cattle. Anim Sci Technol [Jpn] 65: 209-216.

13. Warner ACI (1956) Criteria for establishing the validity of in vitro studies with rumen microorganisms in so-called artificial rumen systems. J Gen Microbiol 14: 733-748.

14. Huggett AG, Nixon DA (1957) Enzymatic determination of blood glucose. Biochem J 66 [Abstract]: 12.

15. Morgan CR, Lazalow A (1963) Immunoassay of 
insulin: Two antibody system. Diabetes 12: 115-126.

16. Sasaki $Y$, Takahashi $H$ (1980) Insulin secretion in sheep exposed to cold. J Physiol [Lond] 306: 323335.

17. Ohneda A, Watanabe K, Wakimatsu M, Fujino M (1979) Production of a specific antiserum by synthetic C-terminal fragment of glucagon. Horm Metab Res 11: 463-468.

18. Ohneda A, Ishii S, Horigome K, Yamagata S (1975) Glucagon response to arginine after treatment of diabetes mellitus. Diabetes 24: 811-819.

19. Kuhara T, Ikeda S, Ohneda A, Sasaki Y (1991) Effect of intravenous infusion of seventeen amino acids on the secretion of $\mathrm{GH}$, glucagon and insulin in sheep. Am J Physiol 260 [Endocr Metab 23]: E21-E26.

20. Gray FV, Pilgrim AF (1951) Fermentation in the rumen of the sheep. II. The production and absorption of volatile fatty acids during the fermentation of wheaten hay and lucerne hay in the rumen. J Exptl Biol 28: 83-90.

21. McAtee JW, Trenkle A (1971) Effect of feeding, fasting and infusion of energy substrates on plasma growth hormone levels in cattle. J Anim Sci 33: 612616.

22. Reynaert R, de Paepe M, Marcus S, Peeters G (1975) Influence of serum free fatty acid levels on growth hormone secretion in lactating cows. J Endocrinol 66: 213-224.

23. Hertelendy F, Kipnis DM (1973) Studies on growth hormone secretion: $V$. Influence of plasma free fatty acid levels. Endocrinology 92: 402-410.

24. Cottrel DF, Gregory PC (1993) Regulation of gut motility by luminal stimuli in the ruminant. In: Tsuda T, Sasaki Y and Kawashima R (eds) Physiological Aspects of Digestion and Metabolism in Ruminants. Academic Press, San Diego, 3-32.

25. Sasaki Y, Takahashi H (1983) Insulin response to secretagogues in sheep exposed to cold. J Physiol [Lond] 334: 155-167.

26. Bloom SR, Edwards AV (1985) Pancreatic neuroendocrine responses to butyrate in conscious sheep. J Physiol [Lond] 364: 281-288.

27. Bassett JM (1975) Dietary and gastro-intestinal control of hormones regulating carbohydrate metabolism in ruminants. In: McDonald IW, Warner ACI (eds) Digestion and Metabolism in the Ruminant. The University of New England Publishing Unit, Armidale, 383-398.

28. Harmon DL (1992) Impact of nutrition on pancreatic exocrine and endocrine secretion in ruminants: A review. J Anim Sci 70: 1290-1301.

29. Sasaki Y, Weekes TEC, Bruce JB (1977) Effects of glucose and butyrate on insulin release from perifused fragments of sheep pancreas. J Endocrinol 72: 415-416.

30. Jordan HN, Phyllips RW (1978) Effect of fatty acids on isolated ovine pancreatic islets. Am J Physiol 234 [Endocrinol Metab Gastrointest Physiol]: E162-E167.

31. Mineo H, Kanai M, Kato S, Ushijima J (1990) Effects of intravenous injection of butyrate, valerate and their isomers on endocrine pancreatic responses in conscious sheep. Comp Biochem Physiol 95A: 411416.

32. Mineo H, Hashizume $Y$, Hanaki $Y$, Murata K, Maeda H, Onaga T, Kato S, Yanaihara N (1994) Chemical specificity of short-chain fatty acids in stimulating insulin and glucagon secretion in sheep. Am J Physiol 267: E234-E241.

33. Sasaki Y, Hiratsuka H, Ishida M (1984) Effect of cold exposure on insulin response to feeding in sheep. Can J Anim Sci 64 (Suppl) 269-270.

34. Reid AM, Titchen DA, Walker D (1984) Effects of dietary protein on basal and post-prandial plasma gastrin and somatostatin in the suckled lamb. Digest Dis Sci 29 (Suppl): 69S.

35. Penman E, Wass KAH, Medbak S, Morgan L, Llwis JM, Besser GM, Ress LH (1981) Response of circulating immunoreactive somatostatin to nutritional stimuli in normal subjects. Gastroenterol 80: 692-699.

36. Uvnas-Moberg K, Anderson B, Poslonclc B (1982) Plasma levels of somatostatin following a test meal in dogs. Initial atropine resistant vagally mediated decrease of somatostatin levels and increase of gastrin and insulin levels. Acta Physiol Scand 114: 253-259. 